\title{
Seismic sensor array for monitoring an avalanche start zone: design, deployment and preliminary results
}

\author{
Alec VAN HERWIJNEN, Jürg SCHWEIZER \\ WSL Institute for Snow and Avalanche Research SLF, Flüelastrasse 11, CH-7260 Davos-Dorf, Switzerland \\ E-mail: vanherwijnen@slf.ch
}

\begin{abstract}
In snow, acoustic emissions originate from the breaking of bonds between snow crystals and the formation of cracks. Previous research has shown that acoustic signals emanate from a natural snowpack. The relation between these signals and the stability of the snowpack has thus far remained elusive. Studies on other hazardous gravitational processes suggest that damage accumulation precedes major failure. If increased cracking activity could be detected in snow this might be used for avalanche prediction. We report on the development of a seismic sensor array to continuously monitor acoustic emissions in an avalanche start zone. During three winters, over 1400 sensor days of continuous acoustic data were collected. With the aid of automatic cameras and a microphone the main types of background noise were identified. Seismic signals generated by avalanches were also identified. Spectrograms from seismic signals generated by avalanches exhibit a unique triangular shape unlike any source of background noise, suggesting that automatic detection and classification of events is possible. Furthermore, discriminating between loose-snow and snow-slab avalanches is possible. Thus far we have not identified precursor events for natural dry-snow slab avalanche release. Detailed investigation of one dry-snow slab avalanche showed that signals observed prior to the release originated from background noise or small loose-snow avalanches.
\end{abstract}

\section{INTRODUCTION}

The release of snow avalanches is a complex critical phenomenon covering several orders of magnitude from the scale of a snow crystal $(0.1 \mathrm{~mm})$ to that of an avalanche slope $(100 \mathrm{~m})$. Although the processes leading to avalanche formation are known qualitatively, predicting exactly when and where an avalanche will release is at present impossible. Snow avalanche release is caused by natural triggers, including snowfall, snow transport by wind and warming, as well as by artificial triggers such as explosives and skiers. For natural slab avalanches it is believed that the initial failure is caused by a gradual damage process at the microscale leading to a localized failure within the weak layer (Schweizer and others, 2003). For avalanches triggered artificially, the external trigger induces localized deformations which are large enough to initiate a failure within the weak layer (van Herwijnen and Jamieson, 2005). In each case, if the crack in the weak layer reaches a critical size it becomes self-propagating and, depending on the slope angle (van Herwijnen and Heierli, 2009), a slab avalanche may release.

The formation and propagation of cracks in a material results in a sudden release of elastic energy and the generation of transient elastic waves, so-called acoustic emissions (e.g. Lockner, 1993). Monitoring acoustic emissions can therefore provide information on the failure process within a material. At the laboratory scale, acoustic emission monitoring has been used extensively to better understand the failure process in various materials such as rock samples (e.g. Lockner, 1993), composite materials (e.g. Woo and others, 2008), wood (e.g. Niemz and others, 2009) or paper (e.g. Rosti and others, 2010). On the larger scale, this technique has also been used to monitor and study gravitational slope instabilities such as landslides (e.g. Spillmann and others, 2007), cliff collapse (e.g. Amitrano and others, 2005), rock avalanches (e.g. Deparis and others,
2008) and unstable glaciers (e.g. Faillettaz and others, 2008). These studies show that acoustic emission monitoring can help to better understand gravitational instabilities and in some cases provide precursory patterns to failure.

Pioneering work during the 1970s revealed that snow under uniaxial compression emits acoustic signals, similar to other materials, and increased acoustic emissions prior to failure as well as a Kaiser effect were observed (St Lawrence and others, 1973; Bradley and St Lawrence, 1975; St Lawrence and Bradley, 1975). Several field experiments ensued with the aim to relate acoustic emissions from a natural snow cover to avalanche formation and slope stability. Increased acoustic emissions were observed during periods of instability (Sommerfeld, 1977; St Lawrence and Bradley, 1977; Gubler, 1979), increased acoustic emission activity was observed without avalanche release (St Lawrence and Williams, 1976) and slope instability was observed without an increase in acoustic emissions (Bowles and St Lawrence, 1977). Given the differences in instrumental set-up and a lack of a thorough description of the field experiments, in particular with regard to the signal processing and the treatment of environmental background noise, results from early seismic studies remain ambiguous.

Recent laboratory experiments have shown the temperature- and density-dependent acoustic emission response of snow under uniaxial compression (Scapozza and others, 2004). Acoustic emissions during the transition from ductile to brittle behaviour have also been studied for homogeneous snow samples (Scapozza and others, 2004) as well as for layered snow samples (Reiweger and others, 2010). Recent field experiments have focused primarily on using seismic methods to detect acoustic signals associated with flowing avalanches for monitoring purposes (Leprettre and others, 1996; Suriñach and others, 2000; Bessason and others, 2007) or to characterize the size and speed of the avalanche (Kishimura and Izumi, 1997; Vilajosana and others, 


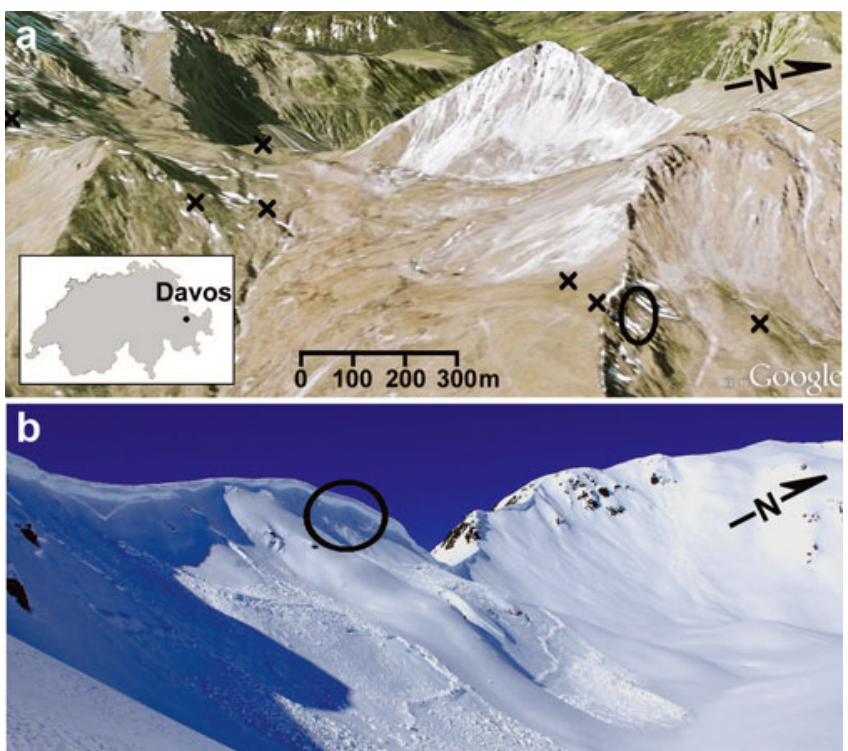

Fig. 1. The geophone array was deployed on a northeast-facing slope in the Wannengrat field site near Davos, Switzerland. (a) Overview of the Wannengrat field site showing the location of seven AWSs (crosses) and the instrumented slope (ellipse). (b) Location of the geophones on the northeast-facing slope (ellipse).

$2007 a, b)$. These recent field studies show that flowing avalanches have characteristic seismic signals and highlight the importance of characterizing background noise (Biescas and others, 2003).

In order to better understand the mechanisms leading to avalanche release, in particular for natural slab avalanche release, and investigate precursors to catastrophic crack propagation, we have developed an acoustic sensor array deployed in an often inaccessible avalanche start zone. We monitored acoustic signals in a natural snow cover continuously during three winters. The long-term aim is to identify precursor signals to avalanche release that can be used for an early warning system. Here, we describe the development of the system and the deployment strategy and we present preliminary results.

\section{FIELD SITE}

Several selection criteria were used to evaluate potential field sites for the seismic sensor array. First, the site required an avalanche start zone which releases at least once per season. Second, the site required easy and safe access for regular field and snowpack observations. Third, the site required automatic weather stations (AWSs) in order to correlate seismic signals with local weather observations (e.g. wind and precipitation). A suitable slope was selected within the Wannengrat field site, located in the eastern Swiss Alps near Davos, Switzerland (Fig. 1). The Wannengrat field site is a test area used extensively by the WSL Institute for Snow and Avalanche Research SLF to study avalanche formation and snow-atmosphere interaction processes (Grünewald and others, 2010). It is instrumented with seven AWSs providing continuous meteorological data.

The study slope $\left(46^{\circ} 48^{\prime \prime} \mathrm{N}, 9^{\circ} 47^{\prime \prime} \mathrm{E}\right)$ is a steep northeastfacing slope on the lee side of a ridge at $2475 \mathrm{~m}$ a.s.l. (Fig. 1). It is a relatively smooth scree slope which receives considerable amounts of snow due to wind loading. The

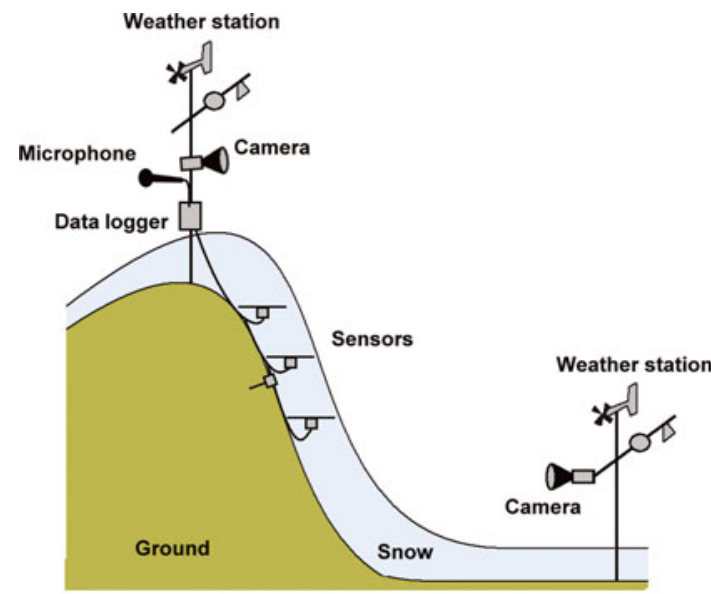

Fig. 2. Schematic system overview of the sensor array. The weather station at the top of the ridge is at $2500 \mathrm{~m}$ a.s.l.; the weather station at the bottom is $200 \mathrm{~m}$ away (horizontal distance) at $2450 \mathrm{~m}$ a.s.l.

slope has consistently produced avalanches in the past, but still there is high uncertainty about the release probability and the exact location. The avalanche start zone is within $50 \mathrm{~m}$ of an AWS at the top of the ridge. Here, instrumentation includes air temperature, humidity, wind speed, wind direction and snow height. In addition, within $200 \mathrm{~m}$ of the site, two additional AWSs record snow surface temperature as well as incoming and outgoing short- and longwave radiation (Fig. 1).

\section{SENSOR ARRAY OVERVIEW}

The harsh alpine environment and a limited power supply affected the design of the sensor array and restricted the choice of equipment. A robust data acquisition system was required to withstand low temperatures, wind and snow. Additionally, low-power equipment was needed since solar power was the only source available.

A prototype low-power single geophone data acquisition system was developed and deployed during the winter of $2007 / 08$. The single geophone provided over 40 days of continuous data from within the snow cover. After this successful test we expanded the system and developed a sensor array consisting of seven sensors and additional observation methods (Fig. 2).

\section{Sensor}

In order to record acoustic signals from within the snow cover, an adequate sensor was required. The main selection criterion when evaluating potential sensors was the frequency range. Signals emanating from a natural snow cover are expected to lie within a wide frequency range. High-frequency signals generally originate from small-scale fractures (i.e. micro-cracks), while large-scale cracking and crack propagation also generates low-frequency signals. High-frequency signals attenuate much more rapidly than low-frequency signals, especially in porous materials such as snow (Iwase and others, 2001). Therefore, high-frequency sensors require a placement close to the source of the signal (i.e. the failure layer of the avalanche), while this is less important for low-frequency sensors. Since the failure layer is not known a priori, or might not have formed at the time of sensor placement, continuous monitoring of high-frequency signals in the snow cover is impractical. 


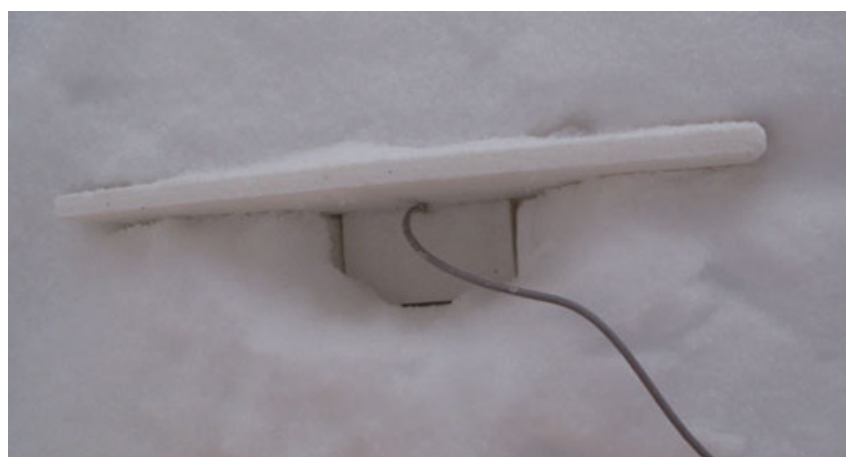

Fig. 3. Geophones inserted in the snow cover were installed in a foam housing. The foam housing improves the coupling between the sensor and the snow cover

The choice of sensor was a trade-off between frequency range and practicality. We used single-component geophones with a natural frequency of $14 \mathrm{~Hz}$ (SM-6 $14 \mathrm{~Hz}$ geophone) which provide a flat frequency response from 14 to over $1000 \mathrm{~Hz}$. Using low-frequency geophones allowed us to install the sensors away from the failure layer. However, the low-frequency range of the sensors did not allow capture of high-frequency signals associated with micro-cracking.

Good coupling between the sensor and the snow improves signal transmission to the sensor. In order to ensure adequate coupling, the geophones were placed in a foam housing (Airex T90.240 foam) with an acoustic impedance close to that of snow (Fig. 3). Preliminary testing with and without the foam housing confirmed the improved signal transmission. When installing the geophones in the field, good coupling between the sensor and the snow was obtained by firmly pressing the foam housing into the snow cover. Changes in the coupling between the sensor and the snow due to snow metamorphism and creep were negligible as no substantial signal degradation or changes in signal amplitude were observed over the course of the winter.

\section{Signal digitalization}

The smallest signals emanating from a snowpack have displacement velocities of order $10^{-6} \mathrm{~m} \mathrm{~s}^{-1}$ (Sommerfeld and Gubler, 1983). Given the sensitivity of the $14 \mathrm{~Hz}$ geophones that were used, such small signals result in an output voltage of about $30 \mu \mathrm{V}$. An amplifier and an analogue-to-digital (A/D) converter were therefore mounted within $1 \mathrm{~m}$ of the sensor to minimize signal deterioration.

For the single-sensor system, the sensor output was digitized using a compact low-power ( $0.4 \mathrm{~W})$ singlechannel digitizing board (Cirrus Logic CRD5378). For the sensor array a commercial data acquisition system based on the same technology (Seismic Instruments SmartGeophone system) was used. The data acquisition system for the sensor array was reliable, robust and had a relatively low power consumption ( $\sim 4.5 \mathrm{~W}$ for seven geophones). For both the single-sensor system and the sensor array, data are sampled at $500 \mathrm{~Hz}$ and an anti-alias filter ensures high-frequency signals are rejected.

\section{Data storage}

Signals associated with damage processes within a natural snow cover are largely unknown. We therefore recorded waveforms continuously rather than using an event-counting system based on a signal threshold value, as was done in early snow-cover seismic studies. To store the seismic data over extended periods of time, a low-power $(\sim 1.5 \mathrm{~W})$ single board computer (SBC) was used (Technologic Systems TS-7260). Data from the single-sensor system were stored on a 32 GB USB flash drive, allowing for close to 300 days of continuous recording. Data from the sensor array were stored on a 32 GB SD card, allowing for 30 days of continuous recording.

\section{Additional observation methods}

In order to separate background noise from signals originating from the snow cover and to determine the location and time of an avalanche, two cameras and a microphone were installed.

The cameras provided valuable information for identifying signals generated by slab and loose-snow avalanches. During the winter of 2008/09, two low-resolution USB webcams (Hercules webcam classic) were connected to the $\mathrm{SBC}$, storing images at $5 \mathrm{~min}$ intervals. One camera was directed at the sensor slope, while the other was directed at a larger northeast-southeast-facing start zone close to the sensor slope. Both cameras were replaced during the winter of 2009/10 with high-resolution stand-alone digital cameras (7 Mpixel Canon Powershot A470).
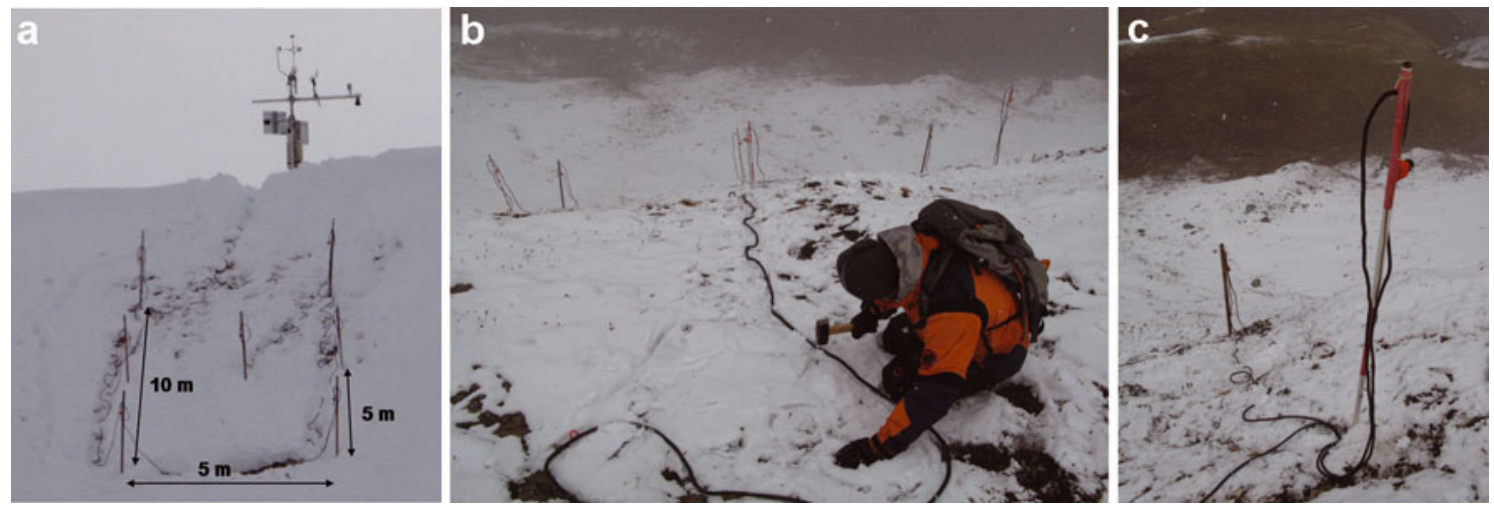

Fig. 4. The first stage of the deployment of the sensor array. (a) The deployment configuration for the winter of 2009/10. (b) Before the first major snowfall the cables of the data acquisition were fixed to the ground. (c) Wooden posts were installed on the ground surface to find the location of the geophones once the cables were covered by snow. 

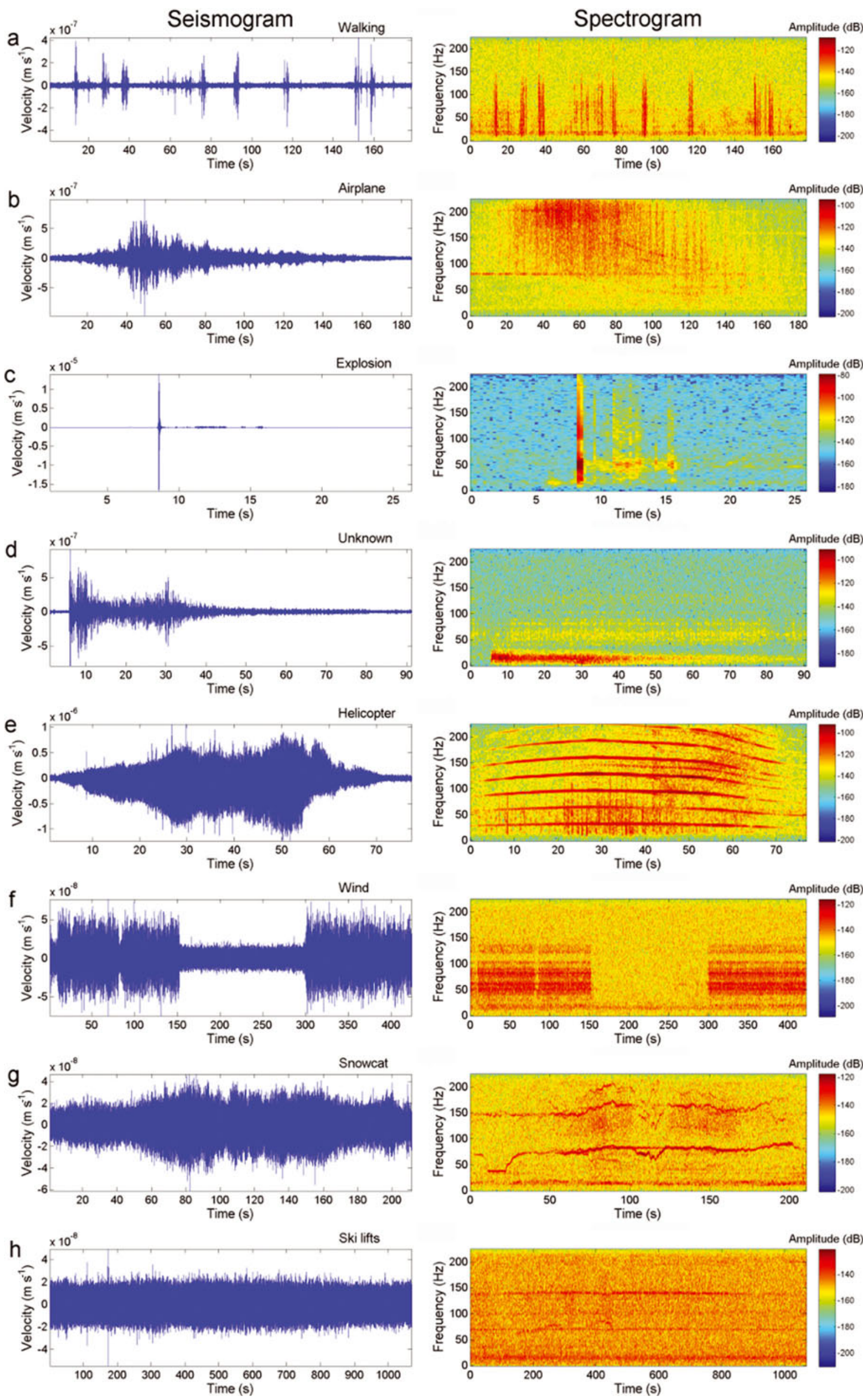

Fig. 5. Examples of the most common seismic signals generated by environmental noise: sources of background noise as indicated in the figure. Seismic signals generated by background noise vary in length and spectral content. 


\section{Pre-avalanche}

\section{Post-avalanche}

\section{Wannengrat}

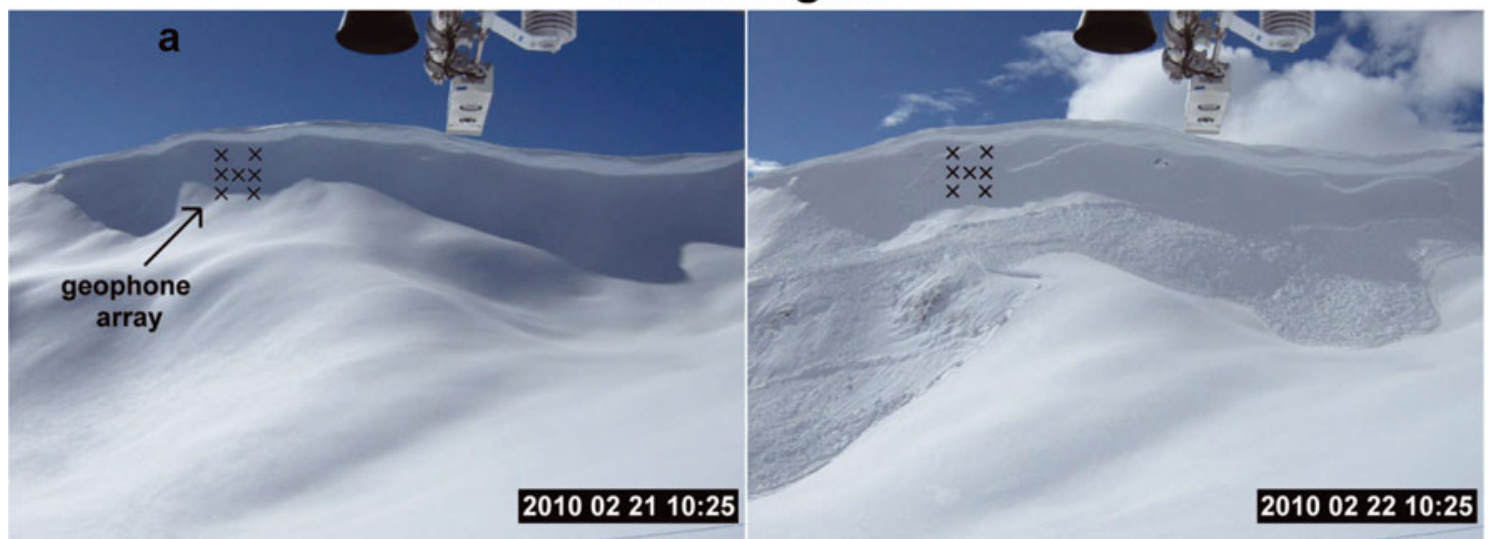

Dorfberg

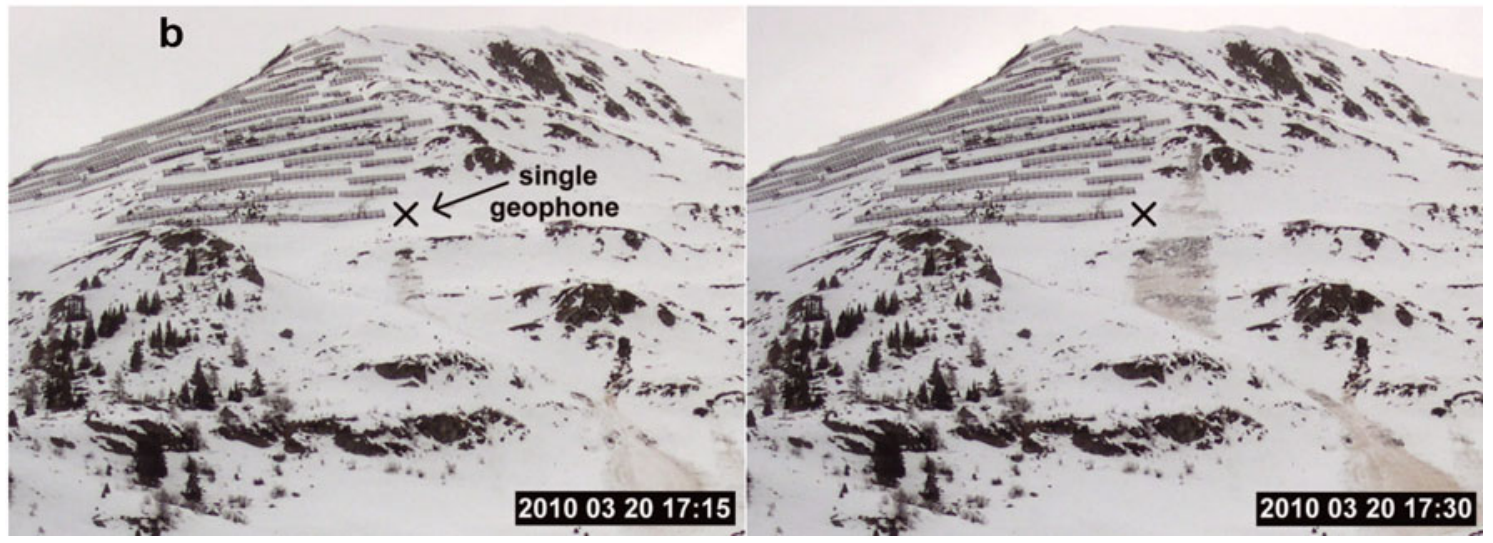

Fig. 6. Two avalanches that released close to the sensors. (a) A slab avalanche released above the geophone array at the Wannengrat field site on 22 February 2010. (b) A loose-snow avalanche released close to the single geophone at the Dorfberg site on 20 March 2010. The black crosses indicate the location of the sensors.

Identification of sources of background noise, such as helicopters and airplanes, was facilitated by installing a microphone. During the winter of 2009/10 a microphone was connected to the SBC using a USB sound card (TerraTec Aureon Dual USB; $\sim 0.3 \mathrm{~W}$ ) and data were recorded continuously at a sampling rate of $8000 \mathrm{~Hz}$.

\section{DEPLOYMENT}

Given the large differences in acoustic properties of the snow cover and the underlying ground cover, the coupling between these two media is weak. In order to optimize signal transmission, especially for low-amplitude signals, six sensors were inserted directly within the snow cover and one in the ground. Since the geophones were located in the snow cover, only P-waves were captured.

The deployment of the sensor array at the Wannengrat field site was carried out in two phases. During the first phase, before the first major snowfall, the cables of the data acquisition system were fixed to the ground and one geophone was inserted into the ground. Wooden posts were installed on the ground surface to facilitate the location of the six geophones during the second phase of the deployment (Fig. 4). When the cables were covered by at least $1 \mathrm{~m}$ of snow, the remaining six sensors were connected to the cables and placed on the snow surface and the wooden posts were removed. The sensors were placed in a rectangular configuration (Fig. 4a) with the sensor inserted in the ground in the middle. Once the sensors were covered by subsequent snowfall, the slope remained undisturbed and the data acquisition was started.

During the winter of 2009/10, a single geophone was also installed on a southeast-facing start zone at a second site, the Dorfberg field site above Davos. This site is used for studying wet-snow avalanches (Mitterer and others, 2009) and the geophone was installed in the ground to provide information on the timing of wet-snow avalanche releases.

\section{PRELIMINARY RESULTS}

During three winters, over 1400 sensor days of continuous acoustic data were collected. Between mid-March and midMay 2008, 42 days of continuous data were collected with the prototype system. Due to minor software and logistical problems, there are gaps in the data. During the winter of 2008/09, data acquisition problems with the geophone array persisted until 23 March 2009. Thereafter, the geophone array collected continuous data until 19 May 2009. During the winter of 2009/10, continuous seismic data were collected at the Wannengrat site from 12 January 2010 until early June 2010, while the single geophone at the Dorfberg site collected data from 15 January 2010 until the end of April 2010. 

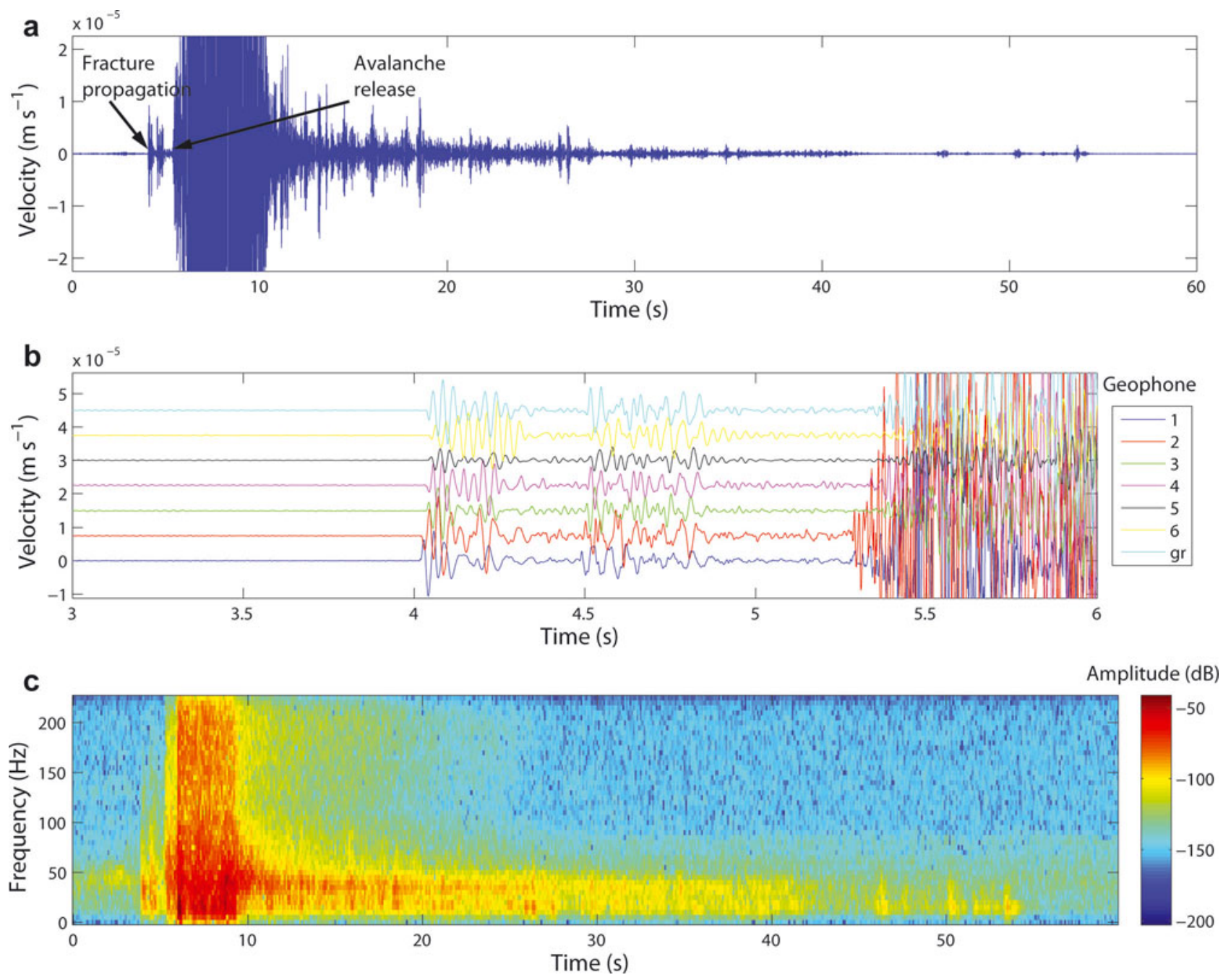

Fig. 7. Seismic signal generated by the slab avalanche at the Wannengrat field site on 22 February 2010 (see Fig. 6a). (a) Seismogram of the entire event from one sensor (geophone 1); first arrivals prior to avalanche release related to fracture propagation are clearly visible. (b) Detailed view of first arrivals shortly before the avalanche release for the seven sensors (gr = geophone in the ground). (c) Spectrogram of the entire event for one sensor (geophone 1); most of the energy is below $50 \mathrm{~Hz}$.

\section{Background noise}

Owing to the low-frequency range of the sensors and the high sensitivity of the data acquisition system, there was considerable background noise in the data. Sources of background noise were identified using three methods. First, signals recorded with the geophones were compared with those recorded with the microphone. Second, data from the two different instrumented sites in Davos were compared. Third, background noise was recorded manually in a field book while in the field. This allowed identification of the main sources of background noise.

Discriminating signals from different sources could not be achieved using an amplitude threshold since the amplitude of the signals is dependent on the proximity of the source and the intensity of the generated signal. In order to eliminate background signals, we compared the seismograms with spectrograms (time-frequency plots), as was done in previous studies (Biescas and others, 2003; Navarre and others, 2009).

The major sources of background noise were: walking, airplane, explosives, unknown, helicopter, wind, snowcat and ski lifts. Each source of background noise generates very distinct spectrograms (Fig. 5). For instance, a person walking on the snow surface typically generates short signals with the main frequency content up to $150 \mathrm{~Hz}$ (Fig. 5a), while helicopters, as well as propeller airplanes, generate longer signals with very distinct harmonic frequencies (Fig. 5e).

\section{Avalanche-generated signals}

Signals associated with numerous avalanches were identified using digital images from the automatic cameras. Here we discuss signals generated by two avalanches, a dry-snow slab avalanche at the Wannengrat site and a wet loose-snow avalanche at the Dorfberg site (Fig. 6).

A relatively large dry-snow slab avalanche released directly above the sensor array at the Wannengrat site on 22 February 2010 (Fig. 6a). The seismic signal generated by the slab avalanche is shown in Figure 7 . The release and downslope sliding of the snow slab resulted in a large signal progressively fading out as the snow slab broke up into smaller fragments and came to a halt (Fig. 7a). Prior to the release of the snow slab, first arrivals in the data, likely associated with fracture propagation through the weak layer, were recorded at all sensors (Fig. 7b). Similar signal characteristics associated with slab avalanche release were documented in the San Juan Mountains, Colorado, USA 

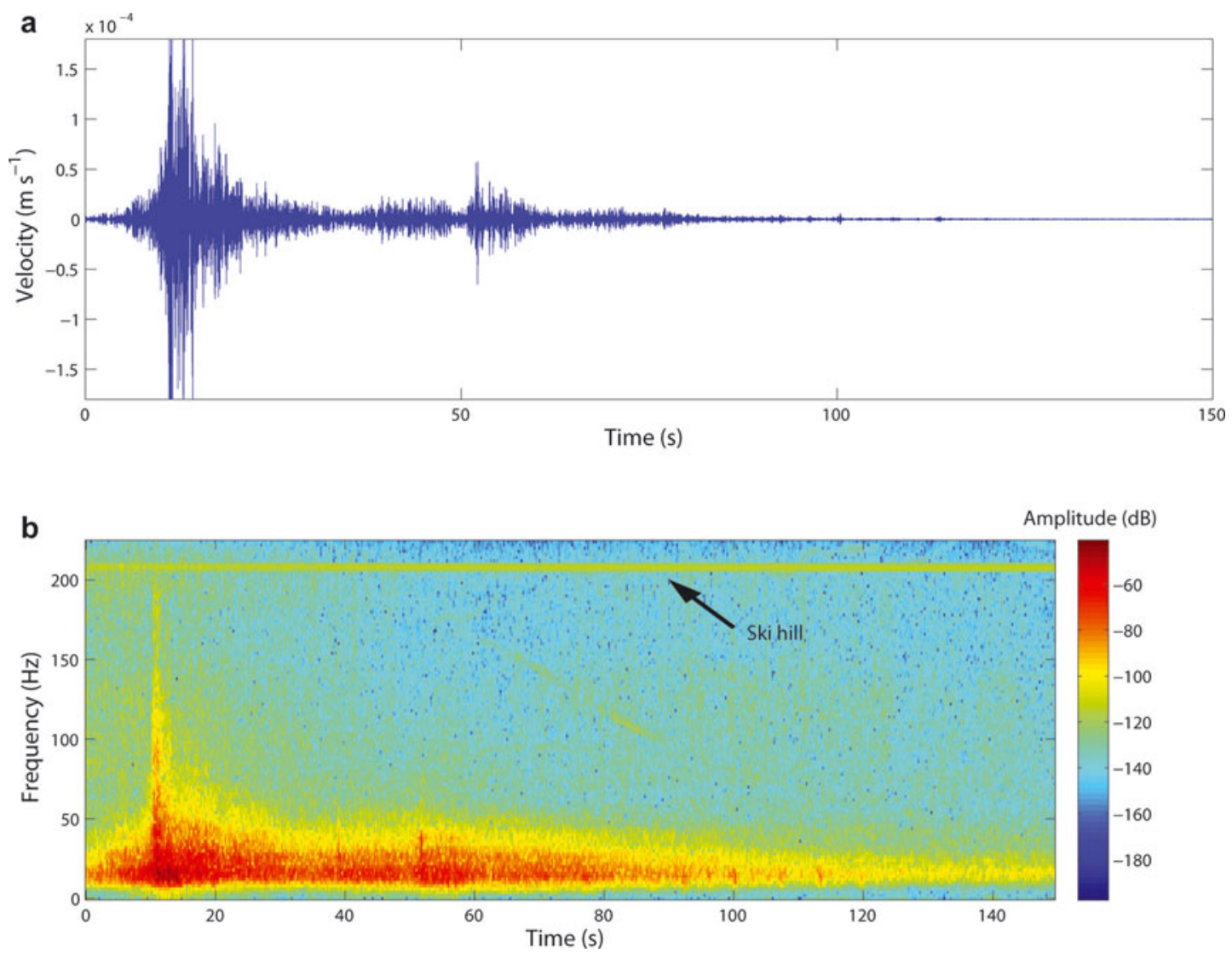

Fig. 8. Seismic signal generated by the loose avalanche at the Dorfberg site on 20 March 2010 (see Fig. 6b). (a) Seismogram of the entire event; typical 'spindle' shape generated by the flowing snow mass. (b) Spectrogram of the event; most of the energy is below $50 \mathrm{~Hz}$.

(St Lawrence and Williams, 1976). The difference in the first arrival of the P-wave and the avalanche release was about $1.4 \mathrm{~s}$. Based on digital images, the width of the avalanche was estimated at $60 \pm 5 \mathrm{~m}$. The time delay between the first arrival of the P-wave and slope failure therefore suggests a fracture propagation speed of $42 \pm 4 \mathrm{~m} \mathrm{~s}^{-1}$, similar to recent experimental results (van Herwijnen and Jamieson, 2005; van Herwijnen and Schweizer, 2010). The frequency content of the signal associated with fracture propagation was mainly below $50 \mathrm{~Hz}$, while the downslope flowing of the avalanche initially generated broadband signals followed by a long low-frequency tail (Fig. 7c).

A large wet loose-snow avalanche released close to the sensor deployed at the Dorfberg site on 20 March 2010 (Fig. 6b). The seismic signal generated by the loose-snow avalanche is shown in Figure 8. The signal increased in magnitude as the avalanche moved downslope towards the sensor and gradually entrained more mass (Fig. 8a). Thereafter, the seismic signal faded progressively as the snow mass passed the sensor and came to a halt. Increases in the signal after the avalanche passed the sensor are attributed to the impact of the flowing snow mass with terrain features (Kishimura and Izumi, 1997). The dominant frequency of the signal increased as the avalanche approached the sensor, while the downslope flow of the avalanche after passing the sensor resulted in a long low-frequency tail, similar to the slab avalanche (Fig. 7).

Seismic signals associated with dry-snow slab and loose wet-snow avalanches show very similar characteristics. The 'spindle' shape in the seismograms and the triangular shape in the spectrograms are typical for seismic signals generated by flowing snow masses (Kishimura and Izumi, 1997; Suriñach and others, 2000; Biescas and others, 2003). This is perhaps due to the attenuation of seismic waves with distance (Biescas and others, 2003). Since the spectrogram generated by an avalanche is different from the typical background noise spectrum (Fig. 5), it is possible to identify avalanches with seismic methods.

Identifying the type of avalanche that released is also possible. The main difference between the seismic signals generated by a snow-slab and a loose-snow avalanche is at the start of the event. Signals associated with slab avalanches start abruptly as the snow slab is released, while signals generated by loose-snow avalanches gradually increase in amplitude as the avalanche entrains more mass. Furthermore, first arrivals in the seismogram associated with fracture propagation through the weak layer prior to avalanche release further distinguish slab avalanches from loose-snow avalanches.

\section{Precursor signals}

In order to investigate possible precursor events, 1 hour of data recorded prior to the release of the February 2010 slab avalanche was explored in more detail (Fig. 9). The slab avalanche released during a storm with wind gusts up to $60 \mathrm{~km} \mathrm{~h}^{-1}$. It therefore comes as no surprise that most signals originated from wind (Fig. 9b).

Two first arrivals in the seismic data recorded 1 hour before the avalanche release were not attributed to noise from wind (Fig. 9c and d). Numerous loose-snow avalanches were observed on the digital images taken the day before the release of the slab avalanche (Fig. 10a). Spectrograms of 


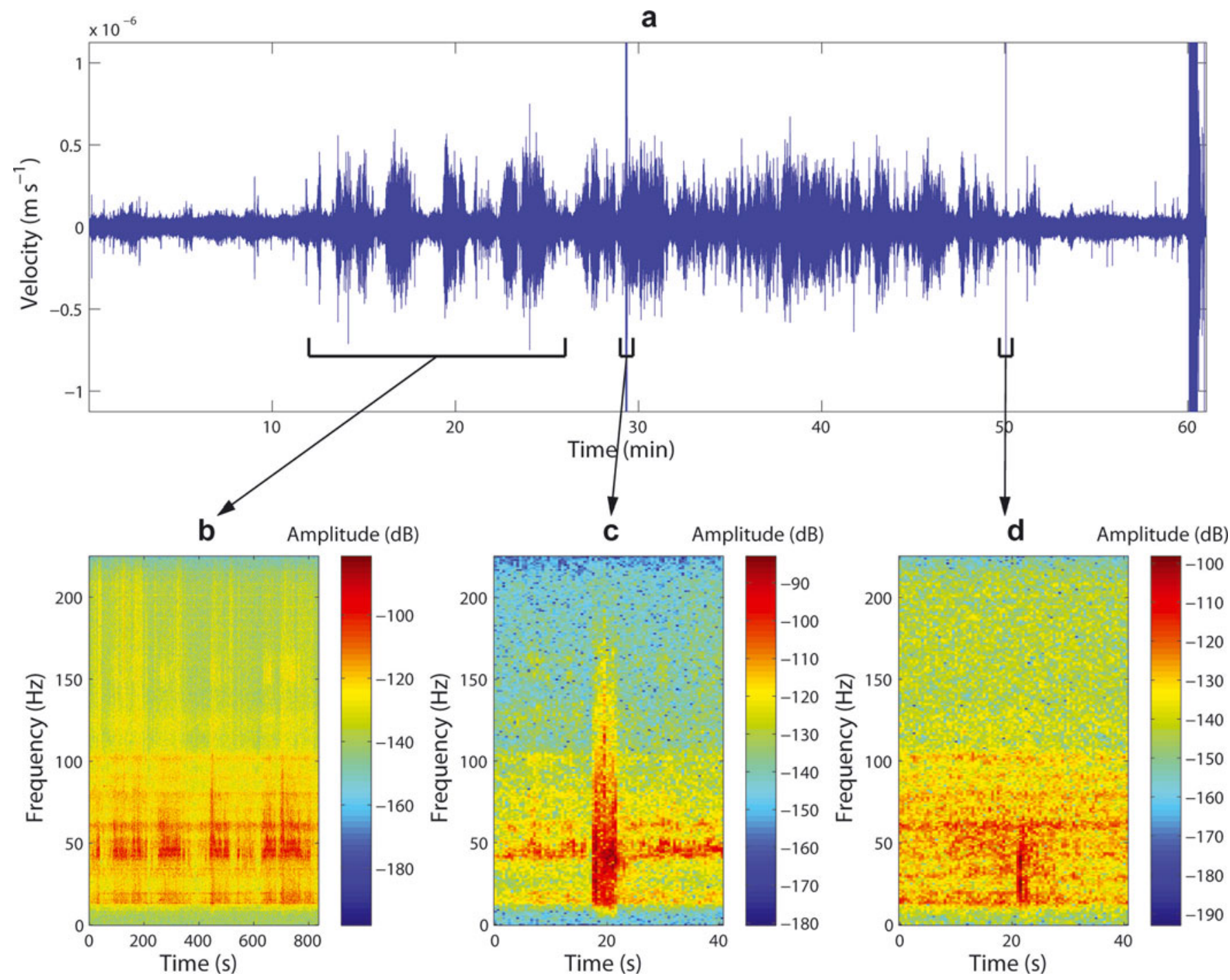

Fig. 9. A detailed view of 1 hour of seismic data prior to the slab avalanche at the Wannengrat field site on 22 February 2010 (see Fig. 6a). (a) Seismogram from geophone 1; three events are highlighted. (b) Spectrogram of first event; spectral content typical for background noise due to wind. (c) Spectrogram of second event; spectral content suggests this was a loose-snow avalanche. (d) Spectrogram of third event; another loose-snow avalanche.

three small loose-snow avalanches (Fig. 10b-d) show remarkable resemblance to the spectrogram of the two events observed shortly before the avalanche release (Fig. 9c and d). This suggests that the first arrivals observed before the release of the avalanche were generated by small loosesnow avalanches. Thus, for this particular slab avalanche, precursor signals associated with crack formation within the snow cover could not be identified.

\section{CONCLUSIONS}

We have described the development and deployment of a seismic sensor array for an avalanche start zone. Over the course of three winters we collected over 1400 sensor days of continuous seismic data from an avalanche start zone. Our preliminary results confirm that seismic instrumentation can be used to continuously monitor an avalanche start zone. For proper analysis of the data, identification of background noise is of paramount importance. Using additional observations methods, i.e. a microphone and automatic cameras, we identified the main sources of background noise.
Seismic techniques using low-cost geophones can detect snow avalanches reliably. Identifying natural avalanche activity up to a distance of $1 \mathrm{~km}$ is possible. Our results show that the spectrograms of seismic signals generated by avalanches exhibit a unique triangular shape, characteristic for flowing snow masses (Kishimura and Izumi, 1997; Suriñach and others, 2000; Biescas and others, 2003), different from the typical background-noise spectrum. These results suggest that automatic detection and classification of events is possible. Furthermore, discrimination between loose-snow avalanches and snow-slab avalanches is also possible. First arrivals associated with fracture propagation through the failure layer were observed in seismic signals generated by snow-slab avalanches and were absent in the seismograms of loose-snow avalanches.

Identification of precursor events for natural dry-snow slab avalanche release was thus far not possible. Detailed investigation of one dry-snow slab avalanche showed that the vast majority of signals observed prior to the release originated from background noise. Two first arrivals prior to the release of the avalanche were likely generated by small loose-snow avalanches, thereby confirming common 

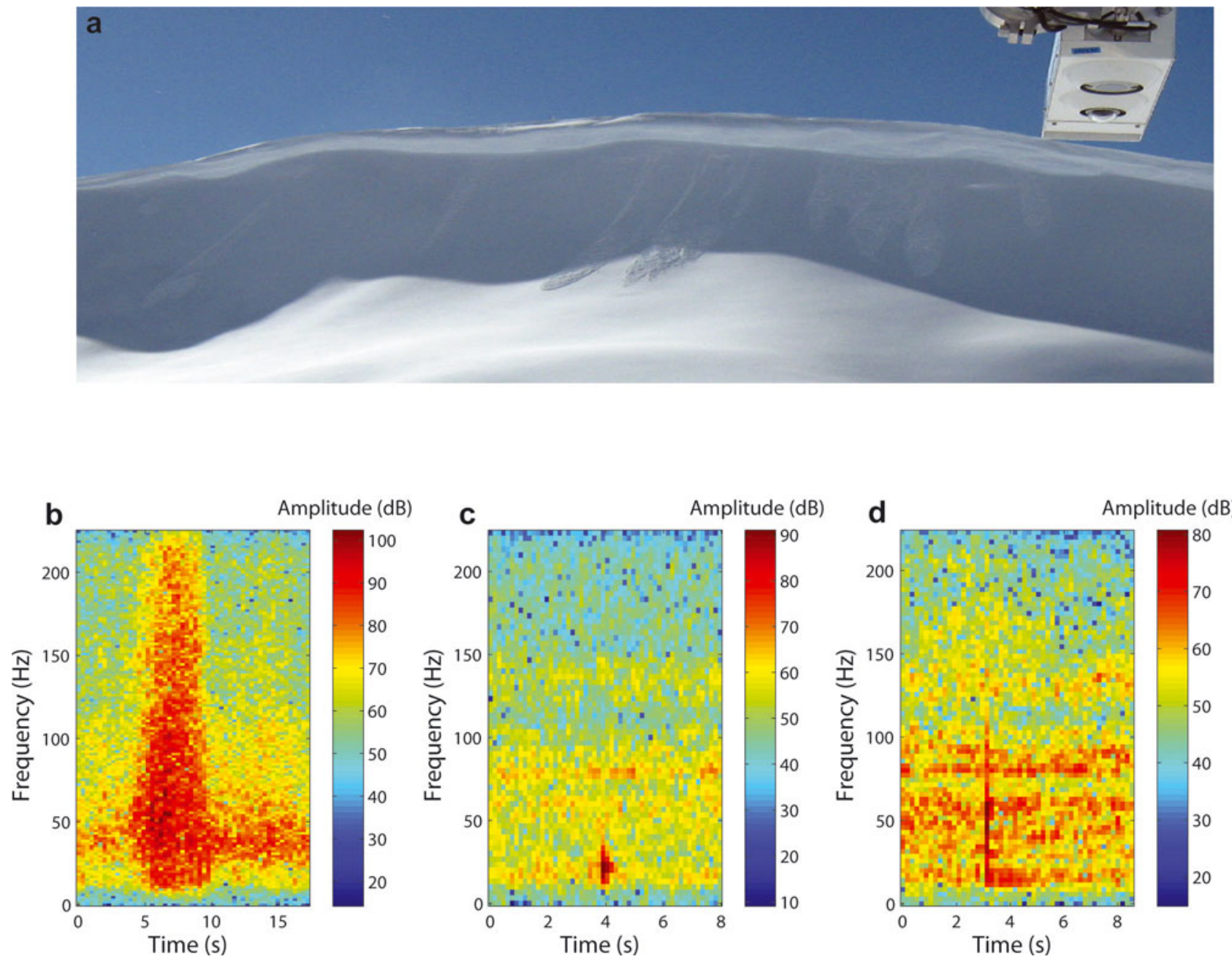

Fig. 10. Loose-snow avalanches observed on the day prior to the slab avalanche at the Wannengrat field site on 22 February 2010 (see Fig. 6a). (a) Owing to the intense wind prior to the avalanche, several loose-snow avalanches occurred on and near the instrumented slope. (b-d) Examples of spectrograms associated with three loose-snow avalanches showing great resemblance to the spectrograms shown in Figure 9c and d.

practice in avalanche forecasting: the best precursors for avalanches are other avalanches.

\section{ACKNOWLEDGEMENTS}

We thank R. Müller (ETH Zürich) and Z. Csizmadia (Seismic Instruments) for their help with the data acquisition and J. Turner for his help with identifying background noise. Funding for this research was in part provided by the FP6 project TRIGS (European Commission contract NEST-2005PATH-COM-043386), the CCES project TRAMM (ETH Board) and the FP7 project HYDROSYS (European Commission grant 224416, DG INFSO).

\section{REFERENCES}

Amitrano, J., J.R. Grasso and G. Senfaute. 2005. Seismic precursory patterns before a cliff collapse and critical point phenomena. Geophys. Res. Lett., 32(8), L08314. (10.1029/2004GL022270.)

Bessason, B., G. Eiríksson, O. Thórarinsson, A. Thórarinsson and S. Einarsson. 2007. Automatic detection of avalanches and debris flows by seismic methods. J. Glaciol., 53(182), 461-472.

Biescas, B., F. Dufour, G. Furdada, G. Khazaradze and E. Suriñach. 2003. Frequency content evolution of snow avalanche seismic signals. Surv. Geophys., 24(5-6), 447-464.
Bowles, D. and W. St Lawrence. 1977. Acoustic emissions in the investigation of avalanches. In Washichek, J.N., ed. Proceedings of the 45th Western Snow Conference, 18-21 April, 1977, Albuquerque, New Mexico. Fort Collins, CO, Colorado State University, 88-94.

Bradley, C.C. and W. St Lawrence. 1975. Kaiser effect in snow. IAHS Publ. 114 (Symposium at Grindelwald 1974 - Snow Mechanics), 145-154.

Deparis, J., D. Jongmans, F. Cotton, L. Baillet, J. Thouvenot and D. Hantz. 2008. Analysis of rock-fall and rock-fall avalanche seismograms in the French Alps. Bull. Seismol. Soc. Am., 98(4), 1781-1796.

Faillettaz, J., A. Pralong, M. Funk and N. Deichmann. 2008. Evidence of log-periodic oscillations and increasing icequake activity during the breaking-off of large ice masses. J. Glaciol., 54(187), 725-737.

Grünewald, T., M. Schidrmer, R. Mott and M. Lehning. 2010. Spatial and temporal variability of snow depth and ablation rates in a small mountain catchment. Cryosphere, 4(2), 215-225.

Gubler, H. 1979. Acoustic emission as an indication of stability decrease in fracture zones of avalanches. J. Glaciol., 22(86), 186-188.

Iwase, T., T. Sakuma and K. Yoshihisa. 2001. Measurements on sound propagation characteristics in snow layer. In Proceedings of the 17th International Congress on Acoustics, 2-7 September 2001, Rome, Italy. CD, 274-275. 
Kishimura, K. and K. Izumi. 1997. Seismic signals induced by snow avalanche flow. Natur. Hazards, 15(1), 89-100.

Leprettre, B.J.P., J.P. Navarre and A. Taillefer. 1996. First results of a pre-operational system for automatic detection and recognition of seismic signals associated with avalanches. J. Glaciol., 42(141), 352-363.

Lockner, D. 1993. The role of acoustic emission in the study of rock fracture. Int. J. Rock Mech. Min. Sci., 30(7), 883-899.

Mitterer, C., R. Mott and J. Schweizer. 2009. Observations and analysis of two wet-snow avalanche cycles. In Schweizer, J. and A. van Herwijnen, eds. Proceedings of the International Snow Science Workshop, 27 September-2 October 2009, Davos, Switzerland. Davos, WSL Institute for Snow and Avalanche Research SLF, 262-266.

Navarre, J.-P., E. Bourova, J. Roulle and Y. Deliot. 2009. The seismic detection of avalanches: an information tool for the avalanche forecaster. In Schweizer, J. and A. van Herwijnen, eds. Proceedings of the International Snow Science Workshop, 27 September-2 October 2009, Davos, Switzerland. Davos, WSL Institute for Snow and Avalanche Research SLF, 379-383.

Niemz, P., A.J. Brunner and O. Walter. 2009. Investigation of the mechanism of failure behaviour of wood based materials using acoustic emission analysis and image processing. Wood Res., $\mathbf{5 4}(2), 49-62$.

Reiweger, I., J. Schweizer, R. Ernst and J. Dual. 2010. Loadcontrolled test apparatus for snow. Cold Reg. Sci. Technol., 62(2-3), 119-125.

Rosti, J., J. Koivisto and M.J. Alava. 2010. Statistics of acoustic emission in paper fracture: precursors and criticality. J. Stat. Mech. Theory Exp., 2010(2), P02016. (10.1088/1742-5468/ 2010/02/P02016.)

Scapozza, C., F. Bucher, P. Amann, W. Ammann and P. Bartelt. 2004. The temperature- and density-dependent acoustic emission response of snow in axial shear tests. Ann. Glaciol., 38, 291-298.

Schweizer, J., J.B. Jamieson and M. Schneebeli. 2003. Snow avalanche formation. Rev. Geophys., 41(4), 1016. (10.1029/ 2002RG000123.)

Sommerfeld, R.A. 1977. Preliminary observations of acoustic emissions preceding avalanches. J. Glaciol., 19(81), 399-409.
Sommerfeld, R.A. and H. Gubler. 1983. Snow avalanches and acoustic emissions. Ann. Glaciol., 4, 271-276.

Spillmann, T., H. Maurer, A.G. Green, B. Heincke, H. Willenberg and S. Husen. 2007. Microseismic investigation of an unstable mountain slope in the Swiss Alps. J. Geophys. Res., 112(B7), B07301. (10.1029/2006)B004723.)

St Lawrence, W. and C.C. Bradley. 1975. Deformation of snow in terms of a structural mechanism. IAHS Publ. 114 (Symposium at Grindelwald 1974 - Snow Mechanics), 155-170.

St Lawrence, W. and C. Bradley. 1977. Spontaneous fracture initiation in mountain snow-packs. J. Glaciol., 19(81), 411-417.

St Lawrence, W. and T.R. Williams. 1976. Seismic signals associated with avalanches. J. Glaciol., 17(77), 521-526.

St Lawrence, W.F., T.E. Lang, R.L. Brown and C.C. Bradley. 1973. Acoustic emission in snow at constant rates of deformation. J. Glaciol., 12(64), 144-146.

Suriñach, E., F. Sabot, G. Furdada and J.M. Vilaplana. 2000. Study of seismic signals of artificially released snow avalanches for monitoring purposes. Phys. Chem. Earth B, 25(9), 721-727.

Van Herwijnen, A. and B. Jamieson. 2005. High-speed photography of fractures in weak snowpack layers. Cold Reg. Sci. Technol., 43(1-2), 71-82.

Van Herwijnen, A. and J. Heierli. 2009. Measurement of crack-face friction in collapsed weak snow layers. Geophys. Res. Lett., 36(23), L23502. (10.1029/2009GL040389.)

Van Herwijnen, A. and J. Schweizer. 2010. Measurement of the deformation field associated with fracture propagation in weak snowpack layers. J. Geophys. Res., 115(F3), F03042. (10.1029/ 2009JF001515.)

Vilajosana, I., E. Suriñach, G. Khazaradze and P. Gauer. 2007a. Snow avalanche energy estimation from seismic signal analysis. Cold Reg. Sci. Technol., 50(1-3), 72-85.

Vilajosana, I., G. Khazaradze, E. Suriñach, E. Lied and K. Kristensen. 2007b. Snow avalanche speed determination using seismic methods. Cold Reg. Sci. Technol., 49(1), 2-10.

Woo, S.-C., N.-S. Choi and N. Cho. 2008. Characterization of the fracture process of notched glass fiber/aluminum hybrid laminates by acoustic emission. Compos. Sci. Technol., 68(6), $1521-1530$. 